\title{
The position of low carb diet in the cancer adjuvant therapy: Clinical nutrition with low carb diet in cancer patients
}

$\underline{\text { Telessy IG }}^{1^{*}}$

${ }^{1}$ Department of Pharmaceutics, Faculty of Pharmacy, University of Pécs, Pécs, Hungary and MedBioFit Lpc. Fácán sor 25. Gödöllö, Hungary

Corresponding author: Telessy IG PharmD, PhD, FICN

Address: Department of Pharmaceutics, Faculty of Pharmacy, University of Pécs, Pécs, Hungary and MedBioFit Lpc. Fácán sor 25. Gödöllö, Hungary.

Received date: 15 February 2019; Accepted date: 11 March 2019; Published date: 18 March 2019

Citation: Telessy IG, "The position of low carb diet in the cancer adjuvant therapy: Clinical nutrition with low carb diet in cancer patients". Asp Biomed Clin Case Rep, vol.2, no.s1: 28-33, 2019.

Copyright (C) 2019 Telessy IG, This is an open access article distributed under the Creative Commons Attribution License, which permits unrestricted use, distribution, and reproduction in any medium, provided the original work is properly cited.

\section{Keywords:}

Low Carbohydrate Diet (LCD); Ketogenic Diet (KD); Glucose Metabolism; Tumor Therapy; Cancer Patient; Clinical Nutrition

\section{Introduction}

Low carbohydrate diet (Low Carb Diet; LCD) is known for ages and exert a positive effect on the health-related quality of life in plenty of people [1]. It is also used over 100 years as a therapeutic tool in various illnesses. In epilepsy this - and the more aggressive version, the ketogenic diet (KD) - is a wellaccepted evidence-based treatment modality for patients suffering from pharmacotherapy resistant type of the illness [2]. LCD is also used as a slimming diet among others under the name "Atkins diet", that has been introduced for public ca. 50 years ago (Atkins Nutritional Approach). However, originally it was developed by cardiologist Robert C. Atkins to publish his concept of healthy eating to help patients with obesity and related health problems (mainly cardiovascular disease, today, in a broader sense, the cardiometabolic syndrome). Public advantages of its moderate version has also been recently demonstrated by NIPPON DATA [3]. Oncological use of carbohydrate-restricted diet started earlier but research activity of Nobel laureate (1924) Otto Warburg supplied the real scientific background to continue this type of therapy in cancer patients. According to his hypothesis tumor cells mainly get energy from anaerobic glycolysis that is not normal in healthy human cells [4]. Of course, we know already that tumor cell metabolism is much more complex.

\section{Physiological Background}

The energy of healthy (static, nonproliferating) cells is produced in mitochondria where the great majority of ATPs are generated definitively via the most efficient aerobic glycolysis. Contrary to this, in the absence of oxygen anaerobic glycolysis supplies much less ATPs and also lactic acid is born that cannot enter into the mitochondrion. Therefore the main energy-producing pathway, the Krebs cycle drops out of the anaerobic process (Fig-1).

The main source of energy for the human body is the carbohydrate-group (sugars, starches, etc.). These substrates are metabolized extracellularly to glucose that enters the cells via glucose transporters (GLUTs). These membrane proteins are present in every cell in various amount and apart of transport 

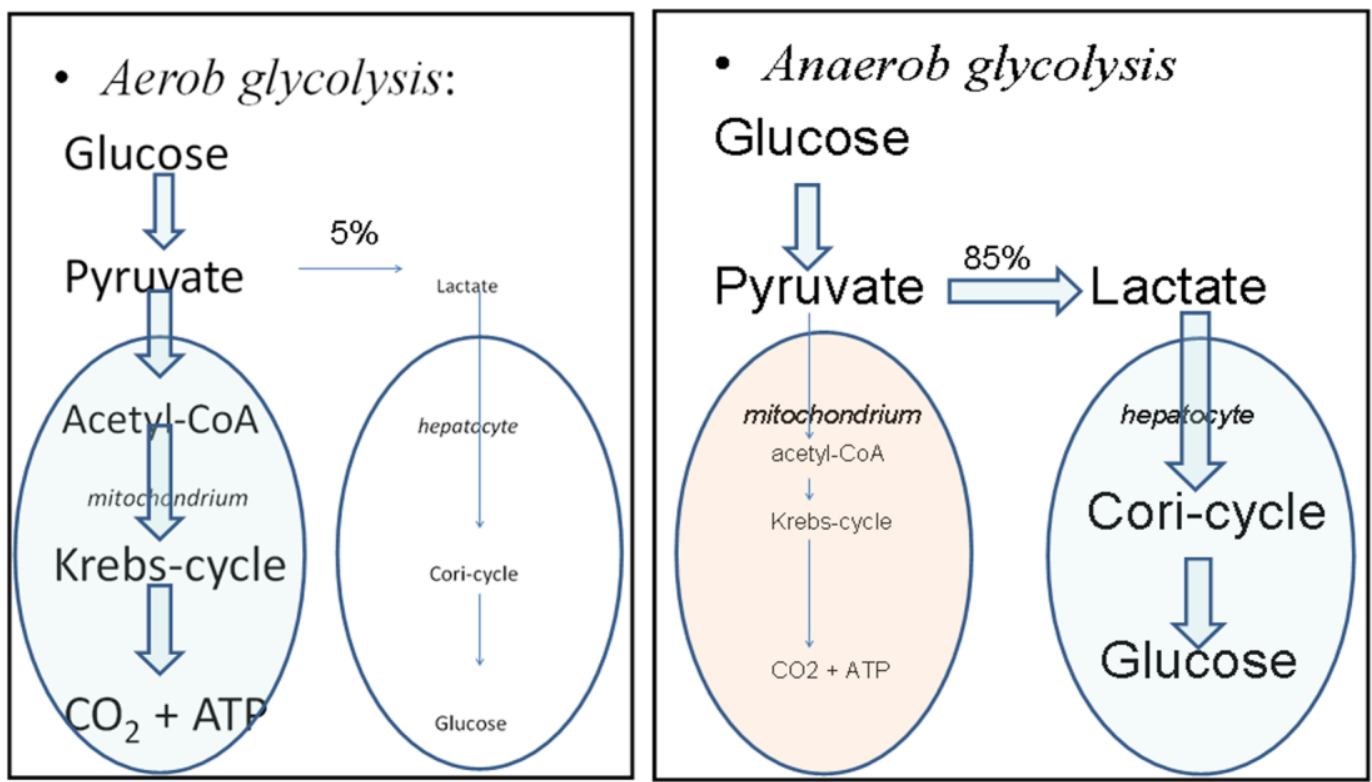

Fig-1: Schematic Comparison of aerob and anaerob glycolysis

functions, they play a role as a receptor, too. Some of the GLUT-proteins concentrate in special cells, like GLUT- 4 in muscle cells and adipocytes, and under special conditions like fasting, GLUT-4 is stored in intracellular vesicles. In case of feeding - based on insulin-signaling - the GLUT-4 molecules move into the plasma membrane and facilitate the entrance of glucose into the cell.

Glucose - in the presence of oxygen - is transformed to pyruvate that enters the mitochondria and metabolized further to acetyl-CoA units that produce - via the Krebs cycle - energy. The whole process - called aerobic glycolysis - produces 10 $\mathrm{NADH}+2 \quad \mathrm{FADH}_{2}+2 \quad \mathrm{GTP}+2$ ATP all together translated to ATP molecules - results in 38 ATPs per glucose molecule in contrast to the anaerobic glycolysis, that produces $2 \mathrm{NADH}+2 \mathrm{ATP}$ all together 8 ATP only beside lactate (Fig-2).

In the mitochondrion, there is another (alternative) energy-producing pathway as well where the raw material is fat, not carbohydrate. In the case of fasting or a sudden need for supplemental energy, this

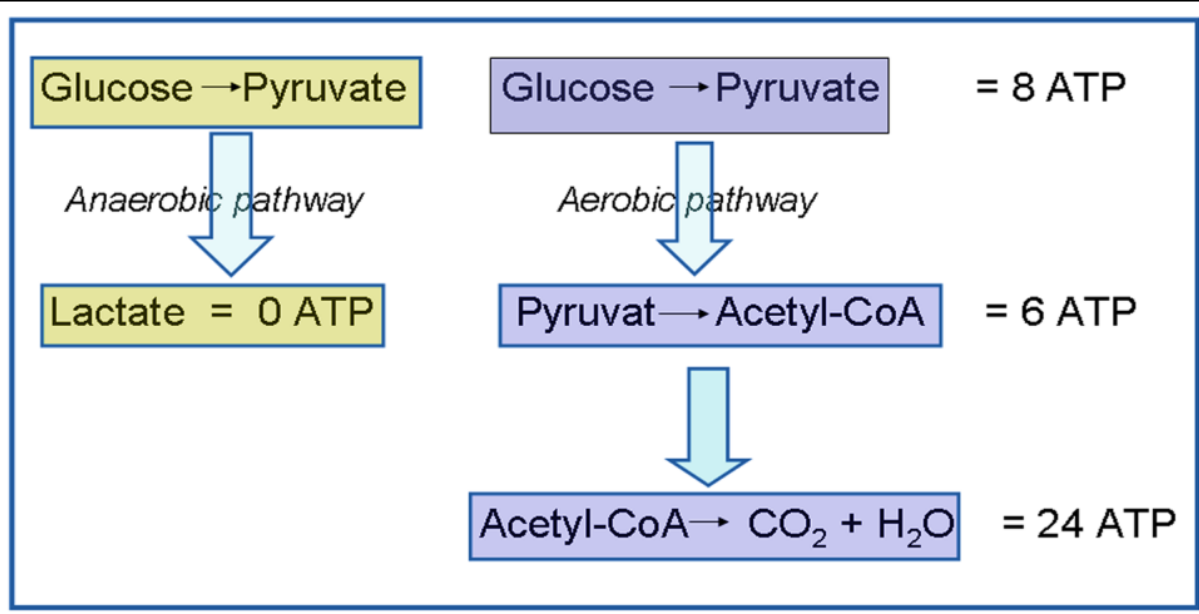

In summary: 1 mol Glucose $=8$ ATP vs 38 ATP

Fig-2: Schematic energy Production in anaerobic and aerobic glycolysis 
Citation: Telessy IG, "The position of low carb diet in the cancer adjuvant therapy: Clinical nutrition with low carb diet in cancer patients”. Asp Biomed Clin Case Rep, vol.2, no.s1: 28-33, 2019.

pathway supply ATPs and ketone bodies (Fig-3). The latter can be utilized by neurons (brain), muscle cells (heart cells, too) and adipocytes. As ketone body (mainly acetoacetate, later acetone and beta- hydroxybutyrate) production needs special mitochondrial enzymes, these molecules are produced in mitochondria only.
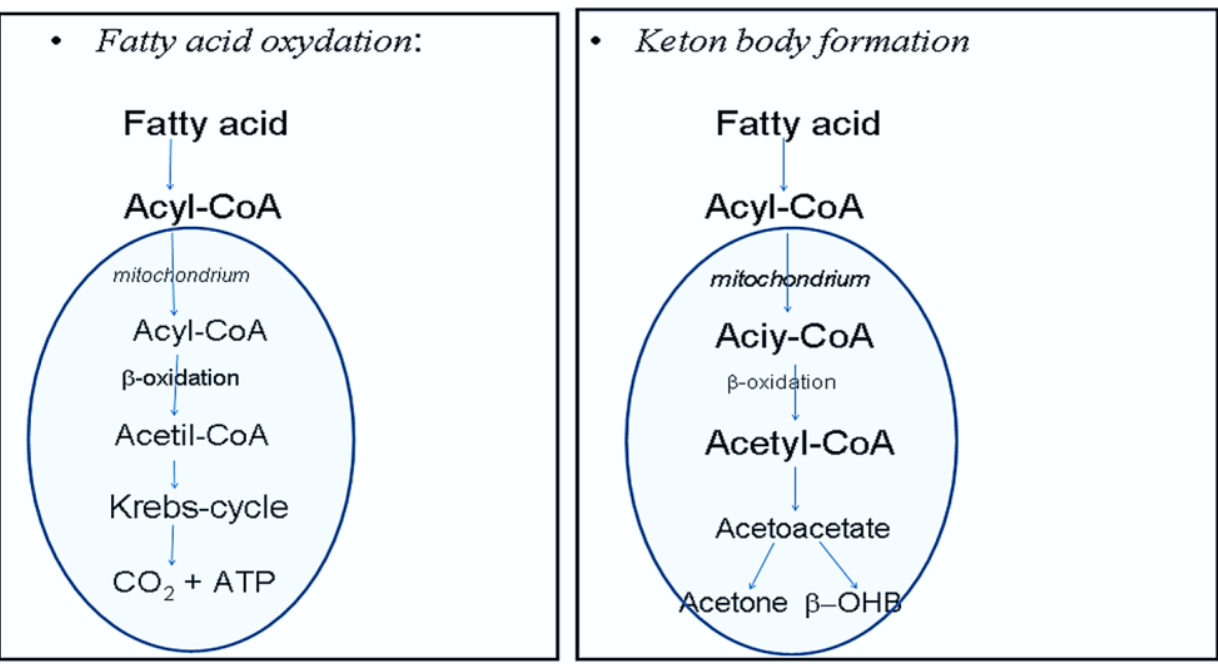

Fig-3: Schematic representation of full decomposition of fatty acids and the keton body formation

\section{Pathophysiological Background in Tumor} Cells

The tumor cells - due to oncogenic mutations that modify the whole metabolism of the cell - prefer the anaerobic form of glycolysis, in concordance with the Warburg hypothesis. As this pathway supply the cell with only 8 ATPs per glucose molecules, a huge amount of glucose input is needed to cover the energy demand of cell proliferation. In tumor cells, the glucose-uptake is decisively excessive compared to the normal cells (this phenomenon is used for detection of tumor cells by positron emission tomography technique using ${ }^{18} \mathrm{~F}$-deoxyglucose as a tracer [5]. This less efficient energy production is virtually against the dictate of „struggle for life” but only in "static cells". In proliferating cells where an increase of biomass has priority, additional benefits join to the cancerous attitude, like the production of

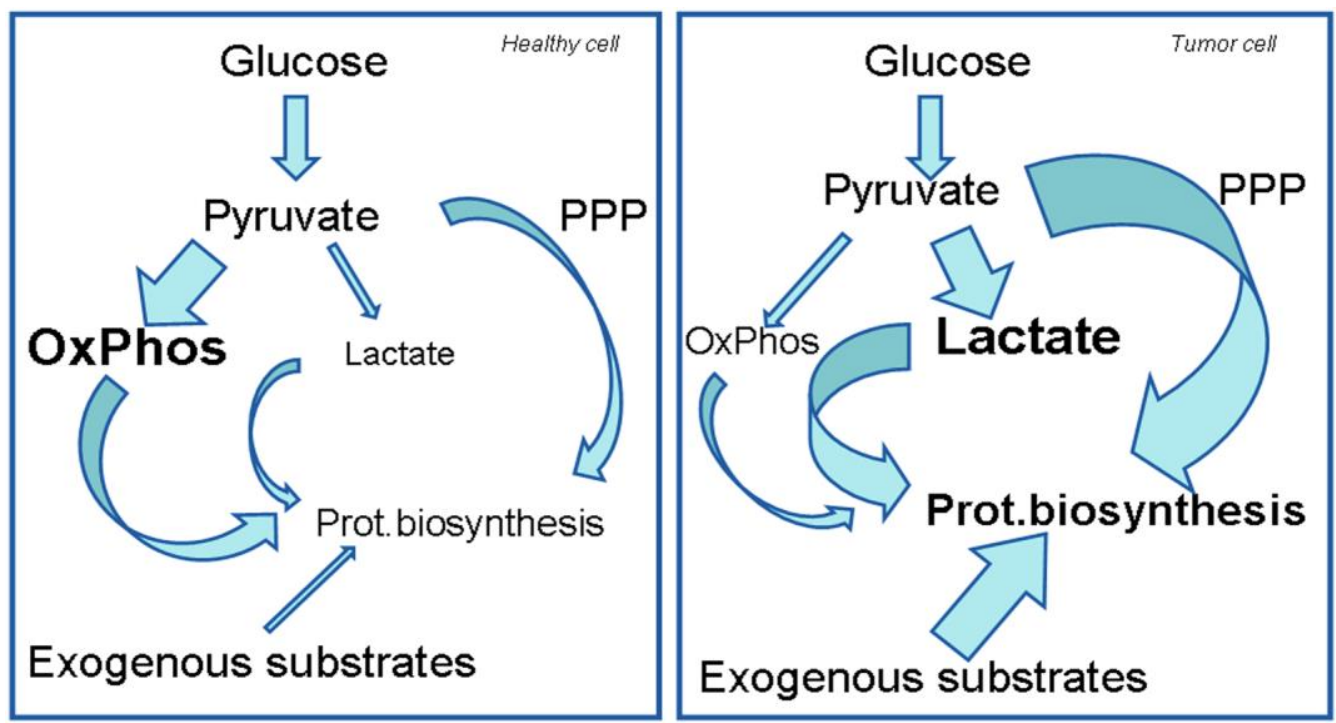

Abbreviations: OxPhos=oxidative phosphorylation $\mathrm{PPP}=$ pentose phosphate pathway

Fig-4: Comparison of glucose metabolism of healthy and cancerous cells 
lactate, use of extra (exogenous) sources (eg. glutamate) for aggressive proliferation, or - from an energetic point of view inefficient - decomposition of glucose. The carbon-bricks (intermediates) originate from the latter process and from glutamate covering carbon-requirements of proliferating tumor cell to build up proteins, ie. new cell structures (Fig-4). This can also justify Warburg-effect [6]. Finally, the point is that in case of tumor cells glucose cannot be regarded just as an energy source but a universal source to build up new cells ie. tumor cells.

\section{Low Carbohydrate Diet (LCD)}

Nutrition which contains less carbohydrate than that covers the requirements of the body cells, first of all, facilitate alternative ways of energy production like fat oxidation. During the beta-oxidation of the fat, a lot of Acetyl-CoA are born and the excess of that can block the citrate-cycle, thus ketone bodies are produced. But in lack of glucose energy-dependent cell proliferation is also blocked. This dual action is the main reason for feed tumor patients with LCD meal. Moreover, fat consumption and mild ketosis due to ketone bodies that are produced via a restricted carbohydrate diet demonstrate anticachectic effect [7]. Besides these, LCD also increases postprandial energy expenditure by transforming dietary protein into carbohydrates. Further, as secondary action consumption of low carb food suppresses appetite by inhibiting gastric emptying what spells into long-lasting satiety following the meal. [8]. Modifications in appetite following LCD may also be caused by changes in hormones such as leptin, PYY, insulin, cholecystokinin, and ghrelin. The secondary effects are beneficial for overweight patients but not for cachectic cancer patients therefore and due to the ketone-body formation one should use LCD carefully, just with a moderate decrease of carbohydrate intake. For those frail patients who need an aggressive ketogenic diet, in our days we have an easy and noninvasive method (acetone breath test) with which therapy can be controlled thoroughly [9].

\section{Clinical Nutrition With a Low Carb Diet}

Today, European eating habits are covered with a macronutrient composition of ca. 50:25:35 enegy $\%$ of carbohydrate:protein: fat respectively. By modification of the composition of food and nutrition, there is a chance to influence the living conditions of cancer cells. We don't know exactly the driver of tumor cells, therefore - at present - curative therapies are very limited, but more and more knowledge is at our disposal about the metabolic pathways and products/byproducts of the tumor cells. Nutrition science supports medical therapy through nutritional therapy. One of the tools is LCD. Per definition, every LCD is - in some measure - a ketogenic diet as it was highlighted above still there are major differences in the composition. The tolerance to ketogenic diets is quite individual for this end tailor-made decision about the therapeutic use of LCD is needed. We have learned that tumor cachexia is an unavoidable and very dangerous situation in this group of patients. Therefore, after diagnosis of cancer as early as possible we must introduce interventions to preserve muscle mass even if we are aware of the fact that against the proinflammatory cytokines produced by the cancer cells and against the metabolic switch we see in tumor cells we can still do not too much. However, by nutrition, we can limit the carbohydrate supply of the cells. And this is as described above, more deleterious/destructive for tumor cells than for healthy cells.

We gave details on carbohydrate restriction that results in a decrease of sources in energy as well as in building blocks for new proteins for proliferating cells. We did not mention but there is some further effect of LCD on immunological and hormonal status and impact in signal-transmission of all life processes, too. All these actions support the clinical use of LCD in the frame of cancer therapy.

Low carb diet in daily clinical practically means that composition of the patient's daily food as well as the artificial nutrition (oral and enteral nutrition) of cancer patients contains fewer carbohydrates but more fat plus more protein than a traditional meal. If due to this modification human organism produced more ketone bodies than previously, the meal is referred to a ketogenic diet. In case the carbohydrate takes less than 
$10 \%$ of meal calories, the food is very low carbohydrate diet (VLCD). This strongly ketogenic type of meal must be taken very seriously because occasionally - for instance in the presence of severe cardiovascular disease, diabetes/prediabetes, fluid, and electrolyte imbalance - harmful effects were also registered. However, in cancer patients more benefits than harms have been detected, eg. no negative influence on the quality of life has been observed in a 12 week randomized, controlled trial with 45 ovarian and endometrial cancer patients on $\mathrm{KD}$ [10]. One other example of the use of LCD is the study of Fine and coworkers [11]. Here 12 tumor patient received a ketogenic diet for 1 month along with the evidencebased traditional anticancer therapy. Nutritional support was successful and safe. In a further study, 16 patients with metastatic carcinoma received special LCD diet with less than $70 g$ carbohydrate per day, for 3 months [12]. The diet was well tolerated and the quality of life improved even if their loss of weight did not change. One more study - some four years ago by means of 20 patients supported the safety and tolerability of LCD moreover synergistic effect has been proved with the angiogenesis-inhibitory bevacizumab therapy [13]. A very recent publication also confirmed the safety and feasibility of $\mathrm{KD}$ in children [14]. Based on these and other experiences the main clinical nutrition manufacturers recently launched low carbohydrate and high fat containing products. All above mentioned examples confirm that with proper nutritional support ( daily $>1,1 \mathrm{~g} / \mathrm{kgBW}$ protein plus $>35 \mathrm{kcal} / \mathrm{kgBW}$ non-protein energy sources, that can be supplied with LCD) decrease of body weight usually can be stopped, furthermore in some cases, depending on the type of cancer, the increase of lean body mass can be reached, too [15].

Today we don't have evidence to declare low carb diet is equally efficacious than surgical, cytostatic or radiotherapy but much more positive than negative clinical experiences were published. Beneficial putative actions against tumor growth were demonstrated - in addition to the above-mentioned safety studies - in a group of brain cancer [16], head and neck cancer [17], breast cancer [18] and thyroid cancer patients [19]. This type of adjuvant therapy to the mentioned classical interventions nutritional therapy is more and more accepted. LCD seems to be a valuable part of nutritional therapy in the multidisciplinary care of tumor [20]. This was concluded from three human cohort studies and 17 animal experiments with caloric restriction and/or ketogenic diets as monotherapy or combination with other therapeutic interventions in the survival of highgrade glioma patients as well [21].

\section{Conclusion}

Cancer patients are predisposed to cachexia. Therefore all therapies inclusive dietary interventions should be planned with the aim to keep or increase fat-free mass. Low carbohydrate diet does not mean low calory diet, therefore, it is in general not contraindicated for this group of patients. On the contrary: due to biochemical advantages moderate LCD is recommended for tumor patients. Several clinical studies confirm that patients tolerate well LCD for a long time and there are definitive benefits of this type of feeding as patients are well nourished without feeding tumor cells. This nutritional modality supports traditional anticancer therapy. This is why most of clinical nutrition product manufacturers offer LCD in their product range.

\section{References}

[1] Ebe K, Bando H, "New era of diet therapy and reasearch including low carbohydrate diet (LCD)". Asp Biomed Clin Case Rep, vol.2, no.S1: 1-3, 2018.

[2] D'Andrea Meira I, Romao TT, Pires do Prado HJ, et al., "Ketogenic diet and epilepsy: what we know so far”. Front Nurosci, vol.13, no.5: 2019.

[3] Nakamura Y, Okuda N, Okamura T, et al., "Low carbohydrate diets and cardiovascular and total mortality in Japanese: a 29-year follow-up of NIPPON DATA8o”. Br J Nutr, vol.112, no.6: 916-24, 2014.

[4] Warburg O, "Über den Stoffwechsel der Tumoren”. Berlin: Springer: 1926.

[5] Derlin T, Grünwald V, Steinbach J, et al., "Molecular imaging in oncology using positron emission tomography”. Dtsch Arztebl Int, vol.115, no.11: 175-81, 2018.

[6] Vander Heiden MG, Cantley LC, Thompson CB, "Understanding the Warburg effect: themetabolic 
Citation: Telessy IG, "The position of low carb diet in the cancer adjuvant therapy: Clinical nutrition with low carb diet in cancer patients". Asp Biomed Clin Case Rep, vol.2, no.s1: 28-33, 2019.

requirements of cell proliferation”. Science, vol.324, no.5930: 1029-33, 2009.

[7] Klement RJ, Kammer U, "Is there a role for carbohydrate restriction in the treatment and prevention of cancer?”. Nutr Metabol, vol.8: 75, 2011. [8] Michalczyk M, Zajac A, Mikolajec K, et al., "No modification in blood lipoprotein concentration but changes in body composition after 4 weeks of low carbohydrate $\operatorname{diet}(\mathrm{LCD})$ followed by 7 days of carbohydrate loading in basketball players". J Hum Kinet, vol.65: 125-37, 2018.

[9] Güntner AT, Kompalla JF, Landis H, et al., "Guiding ketogenic diet with breath aceton sensors". Sensors (Basel), vol.18, no.11: 3655, 2018.

[10] Cohen CW, Fontaine KR, Arend RC, et al., "Favorable effects of a ketogenic diet on physical function, perceived energy, and food cravings in women with ovarian or endometrial cancer: a randomized controlled trial". Nutrients, vol.10, no.9: 1187, 2018.

[11] Fine EJ, Segal-Isaacson CJ, Feinman RD, et al., "Targeting insulin inhibition as a metabolic therapy in advanced cancer: a pilot safety and feasibility dietary trial in 10 patients". Nutrition, vol.28, no.10: 1028-35, 2012.

[12] Schmidt M, Pfetzer N, Schwab M, et al., "Effect of a ketogenic diet on the quality of life in 16 patients with advanced cancer: a pilot trial”. Nutr Metabol, vol.8, no.1: 54, 2011.

[13] Rieger J, Baehr O, Maurer GD, et al., ERGO: a pilot study of ketogenic diet in recurrent glioblastoma. Int J Oncol, vol.44, no.6: 1843-52, 2014.
[14] Van der Louw EJTM, Reddingius RE, Olieman JF, et al., "Ketogenic diet treatment in recurrent diffuse intrinsic pontine glioma in children: a safety and feasibility study". Pediatr Blood Cancer, vol.66, no.3: e27561, 2019.

[15] Breitkreutz R, Tesdal K, Jentschura D, et al., "Effects of a hight-fat diet on body composition in cancer patients receiving chemotherapy: a randomized controlled study". Wien Klin wochenschr, vol.117, no.21: 685-92, 2005.

[16] Woolf EC, Syed AC, "The ketogenic diet for the treatment of malignant glioma". J Lipid Res, vol.56, no.1: 5-10, 2015 .

[17] Klement RJ, "Restricting carbohydrate to fight head and neck cancer - is this realistic?", Cancer Biol Med, vol.11, no.3: 145-61, 2014.

[18] Hyde PN, Lustberg MB, Miller VJ, et al., "Pleiotropic effects of nutritional ketosis: conceptual framework for keto-adaptation as a breast cancer therapy”. Cancer Treat Res Commun, vol.12: 32-39, 2017.

[19] Tella SH, Kommalapati A, Esquivel MA, et al., "Potential role of metabolic intervention in the management of advanced differentiated thyroid cancer”. Front Oncol, vol.7: 16o, 2017.

[20] Bozzetti F, Zupec-Kenia B, "Toward a cancerspecific diet”. Clin Nutr, vol.35, no.5: 1188-95, 2016.

[21] Klement RJ, BrandyopadhyayPS, Champ CE, et al., "Application of Bayesian evidence synthesis to modelling the effect of ketogenic therapy on survival of high grade glioma patients". Theoret Biol Med Model, vol.15, no.1: 12, 2018.

Keywords: $\quad$ Low Carbohydrate Diet (LCD); Ketogenic Diet (KD); Glucose Metabolism; Tumor Therapy; Cancer 